\title{
浅析城市规划设计与建筑设计的关系
}

\author{
隋北京* \\ 华汇结构设计事务所（东营）有限公司，山东 257000
}

\begin{abstract}
摘 要: 随着科学技术的不断推动, 我国经济发展取得了出色的成绩。随着城市化进程的不断深入, 城市化建设 范围逐渐扩张。城市规范反映出城市发展的布局特点, 也能从更深层次中反映出城市的发展特点和人文情怀。在城市 建设当中占据城市用地范围最为广泛的是建筑用地问题, 其中建筑设计的形式与特点将会影响整体城市规划, 城市规 划的进程直接影响建筑设计的质量。因此更应该重视建筑设计与城市规划之间的联系, 以及建筑设计对城市化发展的 重要性。本文主要就城市规划设计与建筑设计之间的关系、正确处理城市规划与建筑设计的方式进行分析。
\end{abstract}

关键词：城市规划设计；建筑设计；关系分析；合理处理

\section{Analysis on the Relationship between Urban Planning and Design and Architectural Design}

\author{
Bei-Jing Sui* \\ Huahui Structural Design Firm (Dongying) Co., Ltd., Dongying 257000, Shandong, China
}

\begin{abstract}
With the continuous promotion of science and technology, China's economic development has made outstanding achievements. With the deepening of urbanization, the scope of urbanization construction has gradually expanded. Urban Norms not only reflect the layout characteristics of urban development, but also reflect the development characteristics and humanistic feelings of the city from a deeper level. In urban construction, the most extensive area of urban land is architectural land. The form and characteristics of architectural design will affect the overall urban planning, and the process of urban planning will directly affect the quality of architectural design. Therefore, we should pay more attention to the relationship between architectural design and urban planning, as well as the importance of architectural design to the development of urbanization. This paper mainly analyzes the relationship between urban planning and architectural design and the correct way to deal with urban planning and architectural design.
\end{abstract}

Keywords: Urban planning and design; Architectural design; Relationship analysis; Reasonable treatment

一、引言

随着生活水平的逐渐提升, 人们对生活质量的需求逐渐转化到建筑设计之中。随着城市化进程的逐渐加深, 相关 部门越发重视城市建设与建筑设计风格的协调性, 充分体现建筑设计的特色 ${ }^{[1]}$ 。城市建筑设计与城市规划的协调性也 是发展创新的必然趋势, 在保障城市建筑美观的程度上更需要满足人民群众的建筑需求, 才能够充分地展现出城市建 筑的局部特点, 充分展示出城市发展的共性与个性需求, 对城市建筑的稳定发展提供重要的支持 ${ }^{[2]}$ 。因此建筑企业应 从城市的发展实际情况进行分析, 使城市规划与建筑设计之间能够充分的融合, 逐渐扩大城市空间的价值, 全面促进 城市规划建设工作的稳定进行。

\section{二、城市规划设计与建筑设计的概念论述}

(一) 城市规划设计概念分析

城市规划内容十分丰富, 其中包含着经济发展、地理环境以及城市交通等。对于城市规划的合理设计能够保障城 市资源的合理利用, 优化城市建设、城市结构以及基础设施的建立, 并根据城市建设需求制定有效的设计方案, 才能

*通讯作者: 隋北京, 1977 年2月, 男, 汉族, 山东东营人, 任职于华汇结构设计事务所 (东营) 有限公司, 助理 工程师, 大专。研究方向: 结构设计。 
全面推动城市经济的稳定发展, 保障居民的生活质量。逐渐提升城市环境质量, 为城市建设的可持续发展贡献重要力 量, 相应可持续发展的基本理念，为全面推进可持续发展奠定充足的基础 ${ }^{[3]}$ 。

城市规划的合理设计不仅影响着居民生活，对经济发展也会产生重要的影响。从城市规划的概念来看，其是指在 一定时期内对城市空间布局的一系列综合性部署, 即对城市空间的分析与设计。从城市规划的角度来看, 其是在可持 续发展的原则上对人们活动的区域空间进行调整, 对城市布局进行科学的规划及设计, 实现政治、经济、社会生活等 方面的协调发展，更好地满足现阶段人们生存发展的需求。

\section{(二) 建筑设计概念分析}

随着城市化进程的不断深人, 最近几年来建筑工程项目类型层出不穷, 随着建筑领域的稳定发展对建筑设计概念 进行全面调整。建筑设计师通过图纸和文件的形式, 将在进行建筑设计过程中最容易出现的问题以及解决方案进行罗 列, 充分减少建筑设计中存在的问题, 充分保障建筑设计的有效实施, 保障建筑设计满足多方面的发展需求 ${ }^{[4]}$ 。对于 人民群众而言在建筑设计中最为关注的内容主要包括建筑风格和建筑结构。但在城市化不断深人的进程中, 建筑设计 领域包含的问题逐渐加深, 设计的问题不断深人, 加剧了建筑设计的整体难度, 传统的简单建筑设计理念已无法满足 现代化建筑发展的需求，现代建筑设计的要求应在设计环节中充分融人历史文化和精神文化等不同的内容。

\section{三、城市规划设计与建筑设计的关系}

(一) 城市规划设计为建筑设计提供指导

就现阶段的城市规划建设当中, 建筑物是形成城市规模的最基础单元对于建筑设计而言, 城市规划当中主要包括 排水设计、园林设计、立体交通设计、路途绿化设计等, 在城市设计过程当中应注重指导工作 ${ }^{\left[{ }^{[}\right]}$。建筑设计不能够只 考虑建筑本身的设计功能, 更应该联合建筑地点范围内的整体区域情况。在建筑设计中间和大情况发展背景下存在着 直接或者间接的联系 ${ }^{[6]}$ 。因此在整体建筑设计过程中, 应充分保障建筑设计与城市规划设计的指导作用, 并为城市规 划提供有效地引导，才能充分协调城市建设中多种设备的建立以及功能结构作用。图1为城市设计指引图表。

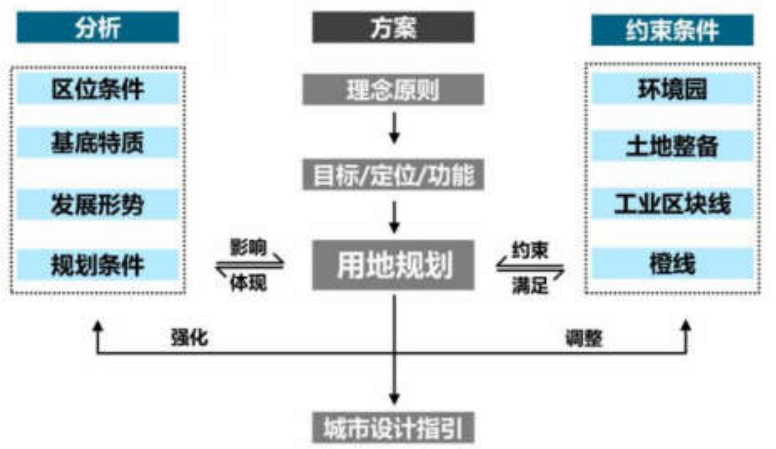

图1 城市设计指引图表

\section{（二）建筑设计为城市规划提供实践理论}

随着建筑发展进程的不断深人, 建筑设计的科学合理性也是现代建筑发展的根本需求。建筑设计方案的完整性不 仅会影响建筑企业的稳定运行, 并且也能够作为可行性的基本规划理念, 以此证明城市规划与建筑设计当中存在着 密切的联系。两者之间存在着较强的互动影响力, 并且在进行设计计划调剂的同时, 往往需要将建筑设计的合理性作 为辨别城市计划发展的条件, 确保建筑设计能够满足城市发展的全面需求 ${ }^{[7]}$, 并为建筑设计提供充足合理化的改造意 见。在进行建筑设计的同时, 应从美学的角度进行分析, 并将两者进行概念的统一与规划。可以根据建筑设计需求进 行美学理念设计, 实现建筑设计中体现业主的意愿, 实现规划设计的统一性, 逐渐提升城市规划水平与建筑设计水 平，保障城市设计的有效内容与城市建设水平相当。

(三) 城市规划设计与建筑设计两者相辅相成

城市规划与建筑设计之间存在着相辅相成的关系, 两者存在着紧密的联系。建筑设计环节是为了促进城市建筑的 发展, 并展示出属于特色的设计风格, 充分满足群众对建筑美的认知, 满足各阶层的群众需要充分体现出创新意识。 同时建筑设计也应当回归到生活当中, 与城市规划紧密相接, 保障规划设计与建筑设计之间存在着内含联系, 保障外 
在风格的统一性。以满足城市发展的需求为前提进行设计, 将城市发展与城市规划进行巧妙融合, 实现建筑设计与城 市规划设计的整体性。建筑设计要从城市规划环节中出发, 严格按照城市设计导则如图2将两者的反应风格进行有效 统一，才能保障城市规划与城市建筑之间的协调发展。

1. 导则制定原则

\section{生态优先原则}

Jisiativition

可持续性原则

开放性原则

过程性原则

\section{2. 城市设计管理控制引导}

（1）整体风格及空间形态设计引导

地块整体建设风格控制

空间形态控制

主要立面控制

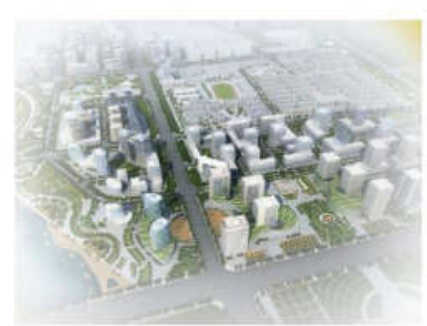

图2 城市设计导则图

\section{四、正确处理城市规划与建筑设计的方式}

\section{(一) 以城市规划设计为参考进行建筑设计工作}

对于设计人员而言在对建筑进行设计的同时, 需要充分的了解并掌握城市发展的整体动向。城市规划设计的主要 内容包括城市未来发展的全新方向, 只有充分地对城市规划进行合理设计才能有效地完成建筑设计工作。并在设计环 节当中相关的建筑物设计也应当顺应城市的发展 ${ }^{[8]}$ 。在设计工作落实之后避免出现建筑物过于突元, 与城市规划设计 不协调的现象出现。并且在进行建筑设计工作之前, 需要将城市的功能区域以及城市的整体布局进行充分的了解, 只 有详细地链接了城市发展规划状况, 才能保障两者之间的充分配合, 为城市规划工作提供建筑设计条件, 保障两者的 协调统一性，只有充分完善城市规划设计工作，才能更全面地进行建筑设计任务。

(二) 完善城市设计工作内涵

在进行城市整体规划设计工作的同时，应遵循社会发展的规律，以及整体性规划的原则。充分考虑城市规划各个 功能区之间的协调性，同时也应当考虑城市规划实际面积、城市功能区功能之间的稳定协调，保障城市规划工作的稳 定进行, 更需要完善城市设计工作的内涵。建筑设计工作的质量严重影响着城市规划设计工作, 以及城市应用功能区 的使用，保障城市设计的实际功能应用。

(三) 加强建筑方案审核力度

在进行建筑设计工作时, 需要建立科学的方案审核制度, 并在实践过程中对方案进行完善。在进行评审任务时, 应建立科学评审小组根据评审流程展开具体的工作。同时可以采取多元化的方式对建筑设计环节进行全面的审核, 保 障建筑类型能够满足城市设计规划的整体需求, 实现城市规划建造焕然一新的根本目标。比如评审人员应根据建筑自 身条件的需求进行分析, 考虑审核方案与建筑设计需求是否合理, 并根据自身的条件考虑施工方案是否可行 ${ }^{[0]}$ 。再者 应考虑建筑设计方案与城市整体规划的内涵相关性，并以建筑设计为基础判断建筑设计与城市发展的协调统一性。同 时也需要对建筑设计市场进行深人调查, 将建筑设计与周围的生态环境进行充分考量, 是否能够将建筑设计融人到城 市整体环境当中。图3为城市规划设计审查流程图。

（四）完善城市规划监管制度

城市规划与建筑设计工作的平衡发展，需要完善的城市规划监管制度作为支持。在进行监督工作中应严格按照相 关的法律条例进行, 并保障城市规划环节的公开透明, 逐渐完善城市规划设计的体系完整。城市规划建筑监管工作需 要多个部门进行充分配合, 只有各部门之间充分发挥优势才能减少城市规划与建筑设计之间的矛盾问题。相关部门也 需要注重宣传工作, 依法进行监督宣传, 提升市民的参与意识, 为城市设计优化和建筑设计提供参考意见, 自觉维护 城市发展。 


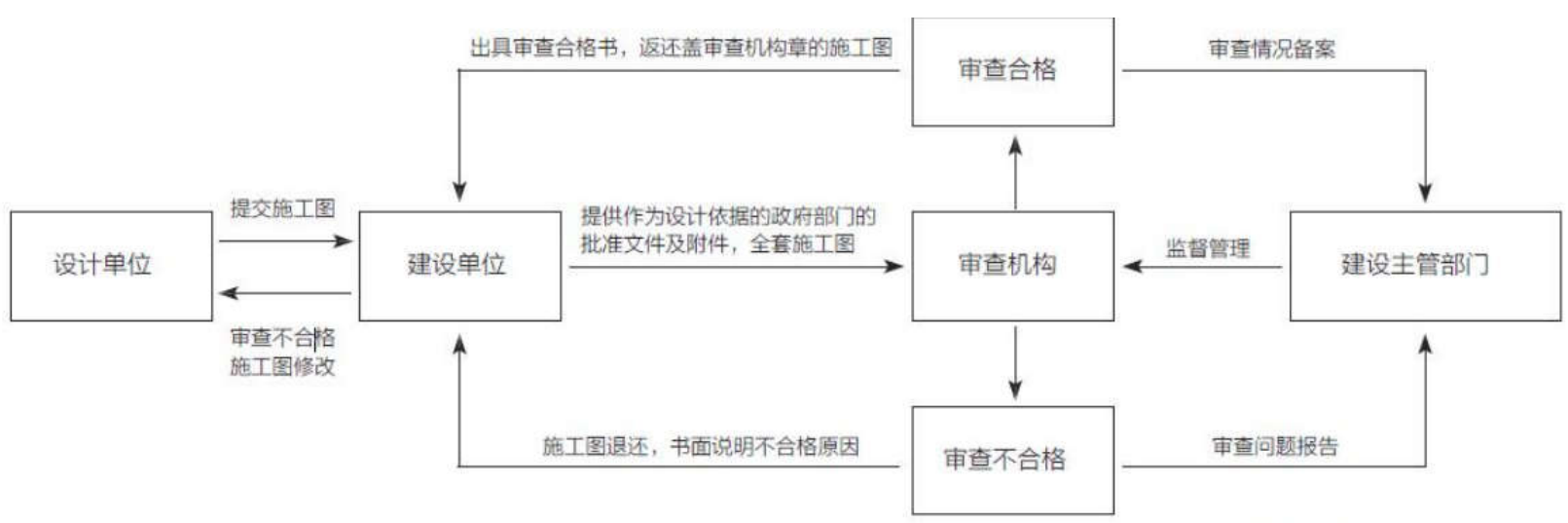

图3 城市规划设计审查流程图

\section{五、结束语}

城市规划与建筑设计之间存在着密不可分的联系, 城市设计优化工作应与城市规划进行协调, 并综合考虑建筑设 计的风格与城市发展的自然、文化、精神文明进行协调, 保障城市规划井然有序地进行。充分凸显出城市规划设计的 核心理念, 充分发挥建筑设计理念的优势, 以此来证明规划设计与建筑设计之间的关联性, 符合新形势下社会发展的 整体趋势。将建筑设计与城市整体规划环节进行充分融合，为建筑设计环节提供合理的支持。

\section{参考文献:}

[1]范否.城市规划设计在建筑工程设计中的应用研究[J].价值工程, 2021,40(13):223-224.

[2]唐永春,贾永慧.生态理念下的城市住宅小区规划及建筑设计要点分析[J].城市住宅, 2021,28(3):187-188.

[3]朱飞.城市规划、城市设计和建筑设计的关系分析 [J].工程建设与设计, 2021(13):34-35,58.

[4]荆莹, 徐漫辰, 侯玉柱, 徐海林. 高质量发展背景下建筑与城市色彩规划设计指引一一郑州航空港经济综合实验区 为例 [J]. 建筑与文化, 2021(7):167-169.

[5]张兆否.城市规划设计与建筑设计的特性和联系探析[J].佳木斯职业学院学报, 2020,36(2):295-296.

[6]黄星火.基于生态理念的城市住宅小区规划及建筑设计要点分析[J].城市住宅, 2020,27(8):144-145.

[7]刘苪.城市规划视角下的建筑群方案设计策略与实践 [J].规划师, 2019,35(z1):22-26.

[8]吴展齐.城市地铁出入口规划与建筑设计分析[J].福建茶叶, 2019,41(7):84-85.

[9]杜娇燕.建筑规划的设计在城市规划建设中的重要性思考初探[J].四川水泥, 2019(3):55. 